\title{
MOBILIDADE E DISPERSÃO ESPACIAL DA POPULAÇÃO: EVIDÊNCIAS COM BASE NA MOBILIDADE PENDULAR METROPOLITANA ${ }^{1}$
}

Carlos Lobo* Ricardo Alexandrino Garcia ${ }^{* *}$ Guilherme Pinto ${ }^{* * * *}$

\section{RESUMO}

As grandes cidades brasileiras, sobretudo aquelas com rápido crescimento demográfico observado a partir de meados do século passado, vêm apresentando nas últimas décadas significativos sinais de dispersão da população em suas periferias. O estudo da redistribuição espacial da população metropolitana no país aponta para essa assertiva. Nesse processo aumentam os níveis de comutação urbana e a mobilidade pendular é um indicador relevante para aferir graus de integração no interior da metrópole. Nesse artigo avalia-se a magnitude atual e as principais características da denominada mobilidade pendular, caracterizada pelos deslocamentos diários da população residente nos municípios de cada Unidade da Federação que trabalha ou estuda no metropolitano. São escrutinados os fluxos do core metropolitano em direção aos municípios periféricos. Para tanto, foram utilizados os microdados amostrais dos Censos Demográficos de 1980, 2000 e 2010, por meio de combinações das variáveis "município de residência e trabalho/estudo". Os resultados indicam forte incremento na mobilidade pendular metropolitana, sobretudo em relação aos municípios mais próximos e que envolvem menores distâncias.

\footnotetext{
${ }^{1}$ Esse trabalho divulga parte do resultado do projeto de pesquisa "Mobilidade espacial da população na Região de Metropolitana de Belo Horizonte" financiado pelo CNPq.

* Doutor em Geografia. Professor Adjunto do Departamento e do Programa de Pós-Graduação em Geografia e Análise e Modelagem de Sistemas Ambientais do IGC/UFMG. E-mail: carlosfflobo@gmail.com.br.

** Doutor em Demografia. Professor Adjunto do Departamento e do Programa de Pós-Graduação em Geografia e Análise e Modelagem de Sistemas Ambientais do IGC/UFMG. E-mail: alexandrinogarcia@gmail.com.

**** Graduando em Geografia pela Universidade Federal de Minas Gerais. Bolsista de Iniciação Científica CNPq.
} 


\section{INTRODUÇÃO}

Desde os anos de 1980, o processo de desconcentração da população e das atividades econômicas no Brasil uma questão que tem atraído a atenção. Além das controvérsias sobre o tema, que resultaram na difusão de expressões como "desmetropolização", "reversão da polarização", "desconcentração concentrada", “dispersão espacial”, dentre outras, há uma evidência empírica incontornável, a do declínio do crescimento populacional de vários centros metropolitanos brasileiros nas últimas décadas por causas diversas, uma das quais diz respeito à migração centroperiferia. Embora o processo de urbanização seja recente no Brasil, os dados referentes aos últimos Censos Demográficos permitiram que alguns autores indicassem sinais de dispersão espacial da população, a despeito de as principais metrópoles, mesmo com crescimento muito baixo, ainda manterem forte expressão demográfica regional/nacional e continuar atraindo milhares de migrantes de regiões deprimidas (Martine, 1994; Diniz, 1993; Matos, 1995a; Lobo, 2009, Lobo e Matos, 2011).

De todo o modo, não excluindo as contribuições dos analistas da economia regional, cabe destacar que esse fenômeno requer aprofundamento quanto às possíveis consequências da redistribuição espacial da população e da mobilidade daqueles sobre influência direta dos municípios metropolitanos ${ }^{2}$. No âmbito da Geografia, são ainda raros os trabalhos sobre esses movimentos e mais incomuns os estudos que exploram determinados quesitos constantes dos censos demográficos produzidos pelo IBGE.

O propósito desse paper é avaliar o nível de dispersão e mobilidade espacial da população que trabalha ou estuda nos núcleos metropolitanos do Brasil tendo como base os deslocamentos pendulares da população de origem nos municípios de cada uma das Unidade da Federação. Para tanto, foram utilizados os microdados amostrais dos Censos Demográficos de 1980, 2000 e 2010. A partir dessas bases foi possível identificar os movimentos específicos de tipo "local de residência para o local de trabalho" que, combinado com a variável "município de residência", conforma-se um quadro sintético

\footnotetext{
${ }^{2}$ De acordo com IBGE, ao estabelecer as Regiões de Influência das Cidades em 2007 (REGIC, 2007), são classificadas como metrópoles: São Paulo (Grande Metrópole Nacional), Rio de Janeiro e Brasília (Metrópoles Nacionais), Belém, Belo Horizonte, Curitiba, Fortaleza, Goiânia, Manaus, Porto Alegre, Recife e Salvador.
} 
sobre a mobilidade pendular no país ${ }^{3}$. Também foram utilizadas as dintâncias rodoviárias obtidas junto ao Departamento Nacional de Estradas de Rodagem (DNER) e epartamento Nacional de Infraestrutura de Transportes (DNIT) ${ }^{4}$. A análise do volume desses fluxos dirigidos às metrópoles brasileiras, de origem de cada Unidade da Federação, permite a problematização da questão da pendularidade metropolitana na análise sobre urbanização e dispersão espacial da população.

\section{MOBILIDADE ESPACIAL DA POPULAÇÃO: A PENDULARIDADE COMO INDICADOR DE DISPERSÃO}

O crescimento continuado da concentração não leva a um perpétuo aumento da eficiência econômica, observava Richardson (1980), um dos primeiros autores a discutir a questão da reversão da polarização. Os benefícios marginais derivados da escala urbana e da concentração tendem a diminuir a partir de certo tamanho de população. Esse processo caracteriza-se por uma mudança de tendência de polarização espacial na economia nacional, desde o momento a partir do qual ocorreria a dispersão espacial para fora da região central. Richardson acreditava que a reversão da polarização se dá em uma sequência de fases: no início haveria um processo bem definido de concentração econômica, quando fora estabelecido um centro e uma periferia; em sequência ocorreriam transformações estruturais na área central, quando os núcleos adjacentes passariam a apresentar crescimento mais acelerado que o centro; o terceiro estágio marcaria o início do processo de reversão da polarização, quando haveria uma dispersão ampliada; na sequência a dispersão também atingiria os centros secundários; e finalmente a área central começaria a perder população. Dessa forma, à medida que as oportunidades de emprego começam a expandir-se mais rapidamente fora da principal área metropolitana, a população residencial tende a redistribuir-se ao longo de todo o sistema urbano, refletindo as crescentes vantagens comparativas das cidades secundárias. Os fluxos de capital e de trabalho convergem para fora da metrópole

\footnotetext{
${ }^{3}$ Nesse trabalho as duas variáveis que identificavam separadamente o local de trabalho e residência dos Censo de 2010 foram combinadas, dando prevalência ao município de trabalho quando era diferente do local de estudo. Essa fusão foi necessária para permitir a comparação com os dados dos Censos Demográficos de 1980 e 2000, que inqueria, em um mesmo quesito, o local de residência ou trabalho. Também para fins de compatibilização não foram separados os movimentos identificados com diários, possível no último levantamento censitário.

${ }^{4}$ Em casos específicos recorreu-se a plataforma do Google Maps.
} 
central até cidades secundárias que experimentariam taxas relativamente mais rápidas de crescimento econômico e demográfico.

No âmbito dos estudos regionais, várias tentativas de aplicação desses modelos e de reconstrução teórica foram utilizadas no Brasil, onde particularidades estruturais e setoriais trazem dificuldades à interpretação desse fenômeno. Um dos primeiros trabalhos sobre o possível processo de reversão da polarização no Brasil foi proposto por Townroe e Keen (1984). Ao considerar esse processo a partir do ponto em que a concentração da população urbana na região central começa a decrescer, esses autores acreditavam que havia sinais concretos de reversão da polarização no Estado de São Paulo entre 1970 e 1980. Eles sugerem a dualidade dos fatores que levam à concentração das atividades econômicas, destacando o papel concentrador representado por determinadas forças sociais e econômicas, que a partir de um ponto passariam a atuar na direção oposta: da desconcentração. A transição demográfica, os graus de desigualdade social e econômica, os padrões de desenvolvimento rural e as formas institucionais e sociais de difusão de informações e inovações podem incrementar ou não a concentração na distribuição da população urbana.

Ainda que possa parecer consensual e bastante atraente, as proposições sobre a reversão da polarização no Brasil sofreram inúmeras críticas. As controvérsias vão desde as evidências empíricas utilizadas até o tipo de variáveis e a metodologias adotadas. Azzoni (1986), por exemplo, critica o fato de o tamanho da cidade ser considerado como indicador de economias aglomerativas. Ao admitir que tais vantagens estão presentes no ambiente urbano, a exemplo da polarização psicológica e do transporte de ideias, é imprescindível considerar a região como capaz de gerar um campo de atração sobre novos investimentos. A ideia essencial é que a atração regional transcende o ambiente urbano, enquanto os custos locacionais são essencialmente urbanos. Seria, no mínimo, apressada a suposição de que haveria um processo de reversão da polarização no Brasil dos anos de 1970. Evidências indicavam que, longe de constituir-se um sinal de reversão da polarização, o fenômeno observado em São Paulo estaria mais próximo de um espraiamento da indústria dentro da área mais industrializado do país, em um processo do tipo "desconcentração concentrada" (AZZONI, 1986).

Diniz (1993), ao contestar alguns dos pressupostos e os resultados apresentados por Azzoni, oferece um novo modelo de interpretação. Entende que, após a incontestável concentração econômica e demográfica verificada até finais da década de 
1960, iniciou-se em um primeiro momento o processo de reversão desta polarização. Entretanto, o processo de desconcentração não teria ocorrido de modo ampliado, e sim, em espaços seletivos bem equipados e ricos em externalidades, refletindo-se no espraiamento rumo ao interior de determinados estados brasileiros. Negri (1996), por outro lado, além de considerar indevida a analogia de Azzoni, acredita ser inapropriado o polígono estabelecido por Diniz. De acordo com Negri, ainda que essa região tenha se beneficiado da desconcentração dos últimos 20 anos, já que ampliou sua participação na indústria nacional de $33,1 \%$ para $49,2 \%$, isto não foi incompatível com o crescimento fora do polígono. ${ }^{5}$

O crescimento urbano acelerado foi uma característica brasileira a partir da década de 1940. A incipiente economia industrial começava a redefinir os rumos da reorganização território e o novo padrão de urbanização fora essencialmente concentrador. Intensificava-se a redistribuição interna da população, em grande medida, em favor dos grandes centros urbanos, notadamente os situados na região Sudeste. Paralelamente programas governamentais incentivavam sucessivas aberturas de fronteiras agrícolas desde a década de 1930 (MARTINE, 1987; PATARRA, 1984, TASCHNER e BÓGUS, 1986). As taxas de crescimento da população urbana, particularmente a partir de 1950, foram muito altas e só vieram a se desacelerar na década de 1970, momento em que o êxodo rural ainda era impressionante e a excessiva concentração demográfica na região Sudeste preocupava autoridades e governos. Mais de $72,0 \%$ da população do Sudeste residia em áreas urbanas e, gradativamente, nas demais regiões também passavam a predominar a aceleração da urbanização.

De acordo com Moura et al. (2005) o estudo da dinâmica metropolitana com base nos movimentos pendulares está vinculado a uma das linhas tradicionais de pesquisa em Geografia Urbana: a identificação de áreas de influência ou regiões funcionais. Adams (1995) considera que "áreas geográficas são definidas, principalmente, em termos de deslocamento diário de casa para o trabalho". Assim, para Frey e Speare Jr., essas transformações na forma de assentamento definiriam um novo conceito de "área metropolitana", caracterizada por alta densidade de movimento

\footnotetext{
${ }^{5}$ Para Matos (1995b) importantes mudanças na distribuição espacial da população estão em curso, sem se conhecer, no entanto, qual é o verdadeiro alcance desse fenômeno, e se as explicações existentes abrangem estes casos. É indiscutível, portanto, que boa parte da expansão da urbanização do país nas últimas décadas deriva dos efeitos multiplicadores de espraiamento da concentração urbana e industrial do Sudeste. Esse processo estimulou o adensamento da rede urbana e os vínculos de complementaridade entre as centralidades.
} 
pendular - considerada como principal indicador da mobilidade e conectividade. Como já demostraram Ojima et al. (2014), o deslocamento pendular com objetivo de trabalho ou estudo é uma importante ferramenta para entender os processos de metropolização, pois permitem verificar o grau de extensão da circularidade de pessoas em uma determinada região. Nos Estados Unidos da América, por exemplo, o Census Bureau define a abrangência e a extensão das Áreas Metropolitanas com base na atualização regular, a cada levantamento censitário, com o uso dos dados de deslocamento pendular para trabalho (OJIMA et al., 2014).

Os deslocamentos diários da população ocorrem nas mais variadas direções e são orientados por diversos motivos: trabalho, estudo, saúde, consumo, lazer, negócios, etc. Esse ir-e-vir constitui elemento integrante da realidade das grandes cidades e reflete, portanto, suas desigualdades sociais e espaciais ${ }^{6}$. Esses deslocamentos constituem-se um indicativo não apenas das trajetórias que as pessoas realizam no espaço, mas também das oportunidades e/ou dos obstáculos (ARANHA, 2005). O processo de ocupação e expansão da metrópole, como demonstra Antico (2004), ligado ao crescimento de áreas do entorno metropolitano, que abrigam grande parte da população sem condições de residir nas áreas mais centrais e valorizadas, aliado à maior concentração de atividades produtivas em determinados espaços centrais. Assim, com o desenvolvimento de um padrão locacional de ofertas no mercado imobiliário em áreas mais afastadas e desvalorizadas, os trabalhadores pendulares utilizam como estratégia residir nos locais mais acessíveis, percorrendo maiores distâncias para chegar ao município de trabalho.

\footnotetext{
${ }^{6} \mathrm{~A}$ mobilidade cotidiana está associada à mobilidade residencial e as migrações intrametropolitanas, que normalmente não mudam o espaço que potencialmente se desenvolve a vida dos indivíduos que mudam de habitação ou residência. Embora o trabalho tenha centralidade nos deslocamentos cotidianos, a mobilidade cotidiana é muito mais ampla. Envolve as diferentes ações do dia a dia dos indivíduos. Portanto, as migrações pendulares fazem parte da distribuição espacial da população, em seus múltiplos aspectos, cujas modalidades estão inter-relacionadas, sejam migrações internas, mobilidades residenciais, cotidiana e do espaço de vida. Neste sentido, os deslocamentos da população estão relacionados à produção da existência, que envolve diferentes temporalidades sociais advindas das condições de vida e de trabalho refletindo os movimentos da economia e da sociedade (JARDIM E ERVATTI, 2006).
} 


\section{MOBILIDADE E DISPERSÃO? EVIDÊNCIAS COM BASE NOS FLUXOS E DISTÂNCIAS DA PENDULARIDADE METROPOLITANA}

Com base na análise dos dados expostos na Tabela 1, que apresenta o número dos deslocamentos pendulares com destino a cada uma das metrópoles brasileiras, notase um importante incremento geral dos fluxos. Se em 1980 esses descolamentos envolviam pouco mais de 1,5 milhão de pessoas, em 2010 esse número era superior a 3,5 milhões. Em termos absolutos, destacam-se os volumes de Rio de Janeiro e São Paulo. Esse último município, recebia regularmente mais de 1 milhão de indivíduos não residentes para trabalho ou estudo. Nota-se, contudo, que o maior ritmo de crescimento médio anual desses fluxos foi com destino Manaus $(14,95 \%$ a.a.) e para Salvador e Goiânia (ambos com 5,44\% a.a.).

Quando considerados os percursos envolvidos nesses deslocamentos, os resultados, em geral, indicam redução das distâncias ponderadas, a exceção Manaus e Rio de Janeiro. Essa redução das médias ponderadas, não representa, contudo, redução nos volumes de deslocamentos em trajetos mais distantes, mas sim crescimento dos fluxos para municípios do entorno imediato. Como esses fluxos envolvem números mais expressivos, os valores das médias sofrem reduções.

Tabela 1: Mobilidade Pendular metropolitana - Número e Distância Média Ponderada (DMP) daqueles que tralham ou estudam no núcleo metropolitano e residem nos demais municípios da respectiva Unidade da Federação, 1980, 2000 e 2010

\begin{tabular}{|l|r|r|r|r|r|r|r|r|r|}
\hline \multirow{2}{*}{ Metrópole } & \multicolumn{3}{|c|}{ Mobiliade Pendular $\left(\mathrm{n}^{\text {o }}\right.$ de pessoas) } & Crescimento Anual $(\%)$ & \multicolumn{3}{|c|}{ DMP $(\mathrm{Km})$} \\
\cline { 2 - 9 } & 1980 & 2000 & 2010 & $1980 / 2000$ & $2000 / 2010$ & 1980 & 2000 & 2010 \\
\hline Belém & 15.988 & 89.865 & 120.564 & 9,02 & 2,98 & 98,50 & 36,05 & 44,56 \\
\hline Belo Horizonte & 102.806 & 300.565 & 429.565 & 5,51 & 3,64 & 72,01 & 51,18 & 52,11 \\
\hline Curitiba & 47.573 & 167.496 & 260.398 & 6,50 & 4,51 & 70,42 & 43,02 & 11,47 \\
\hline Fortaleza & 25.674 & 76.350 & 128.567 & 5,60 & 5,35 & 113,62 & 58,97 & 57,55 \\
\hline Goiânia & 14.207 & 113.183 & 192.289 & 10,93 & 5,44 & 71,15 & 35,43 & 33,57 \\
\hline Manaus & 1.035 & 2.525 & 10.170 & 4,56 & 14,95 & 282,40 & 398,11 & 371,83 \\
\hline Porto Alegre & 132.989 & 213.408 & 270.057 & 2,39 & 2,38 & 37,88 & 40,55 & 37,12 \\
\hline Recife & 153.859 & 239.552 & 324.255 & 2,24 & 3,07 & 26,68 & 26,97 & 26,19 \\
\hline Rio de Janeiro & 534.993 & 524.587 & 682.412 & $-0,10$ & 2,67 & 35,54 & 40,05 & 41,66 \\
\hline Salvador & 22.737 & 54.804 & 93.077 & 4,50 & 5,44 & 160,43 & 133,44 & 128,21 \\
\hline São Paulo & 450.622 & 695.148 & 1.030 .383 & 2,19 & 4,01 & 45,31 & 46,12 & 44,79 \\
\hline Total & 1.502 .483 & 2.477 .483 & 3.541 .738 & 2,53 & 3,64 & 92,18 & 82,72 & 77,19 \\
\hline
\end{tabular}

Fonte: IBGE, Censos Demográficos de 1980, 2000 e 2010 (dados da amostra) 
A análise da Figura 1, que representa a proporção da mobilidade pendular na população residente (Figura 1a) e conectividade pendular dos municípios de cada Unidade da Federação que abrigam residentes que trabalham ou estudam na respectiva metrópole (Figura 1b), permite observar o crescimento da participação da mobilidade pendular na realidade das metrópoles brasileiras. Em todos os casos ocorreu crescimento relativo de populações que residem no interior de cada estado e que trabalham ou estudam no município metropolitano sobre a população residente na metrópole. No caso de Recife essa razão é superior a 20\%. Também merecem ser mencionados: Porto Alegre, Belo Horizonte, Curitiba, Goiânia e Rio de Janeiro (todos com mais de 10\%). É também considerável a proporção de municípios de cada Unidade da Federação em que residem aqueles que se deslocam regularmente para a metrópole. Nos casos de Rio de Janeiro, Manaus, Fortaleza, Recife e Goiânia esse percentual é superior a $90 \%$.

\section{RAZÃO DE PENDULARIDADE}

Figura 1a

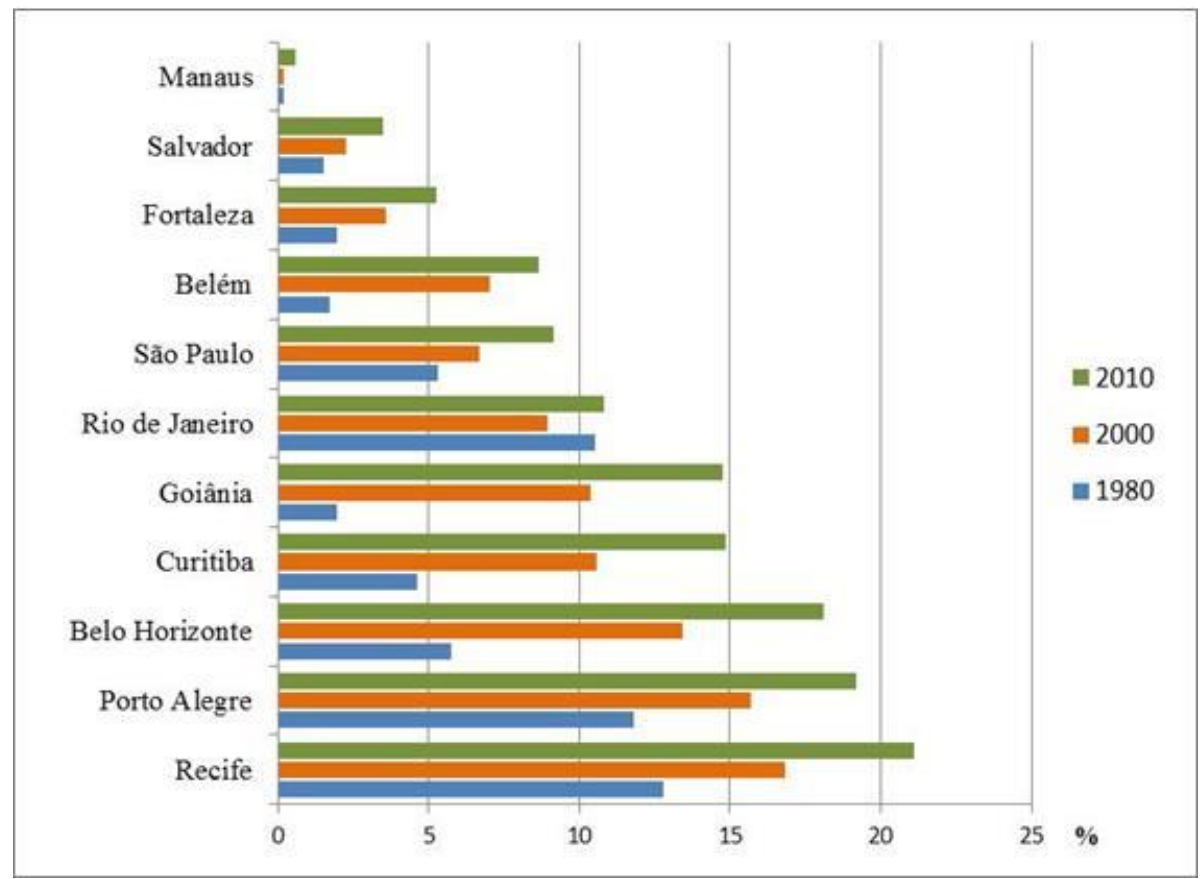


RAZÃO DE CONECTVIDADE PENDULAR

Figura $1 \mathrm{~b}$

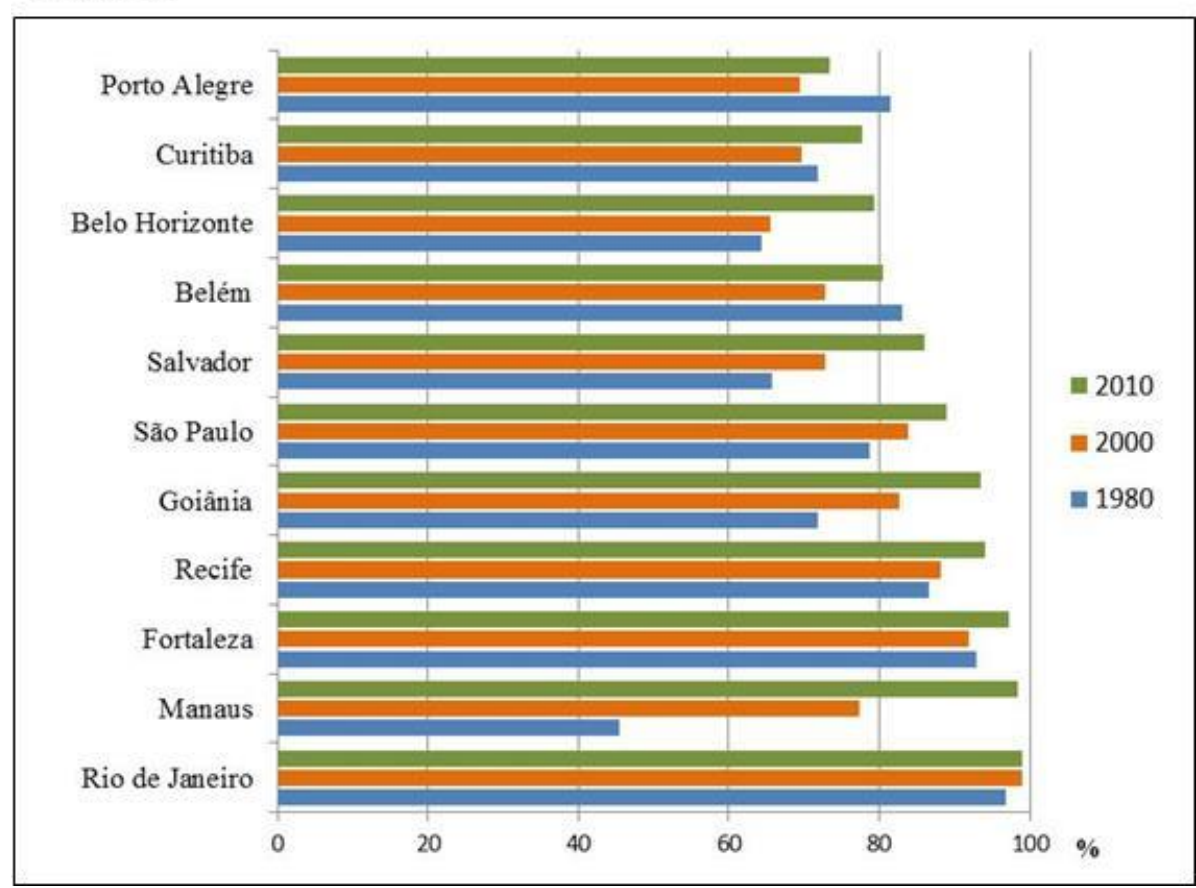

Figura 1: Razão de Pendularidade e Conectividade Pendular dos núcleosmetropolitanos Brasileiros, 1980, 2000 e 2010

Fonte: IBGE, Censos Demográficos de 1980, 2000 e 2010 (dados da amostra)

A Figura 2 identifica a intensidade da mobilidade que envolve a metrópole paulista e os municípios do interior do estado. Trata-se de um caso bastante peculiar, tanto pela magnitude dos fluxos, como pelo alto nível de conectividade envolvida. Em 1980 a mobilidade pendular com destino a capital paulista englobava um total de 449 municípios. Nas duas décadas seguintes, de 2000 e 2010, esses fluxos incorporavam, respectivamente, 541 e 574 municípios. Chama atenção, além dos municípios que compõem a RMSP, aqueles localizados ao longo dos principais eixos rodoviários do Estado de São Paulo, como a Dutra, Anhanguera/Imigrantes e Castelo Branco, que com os investimentos nos últimos anos facilitou e tornou mais ágil a mobilidade para trabalho e estudo. 


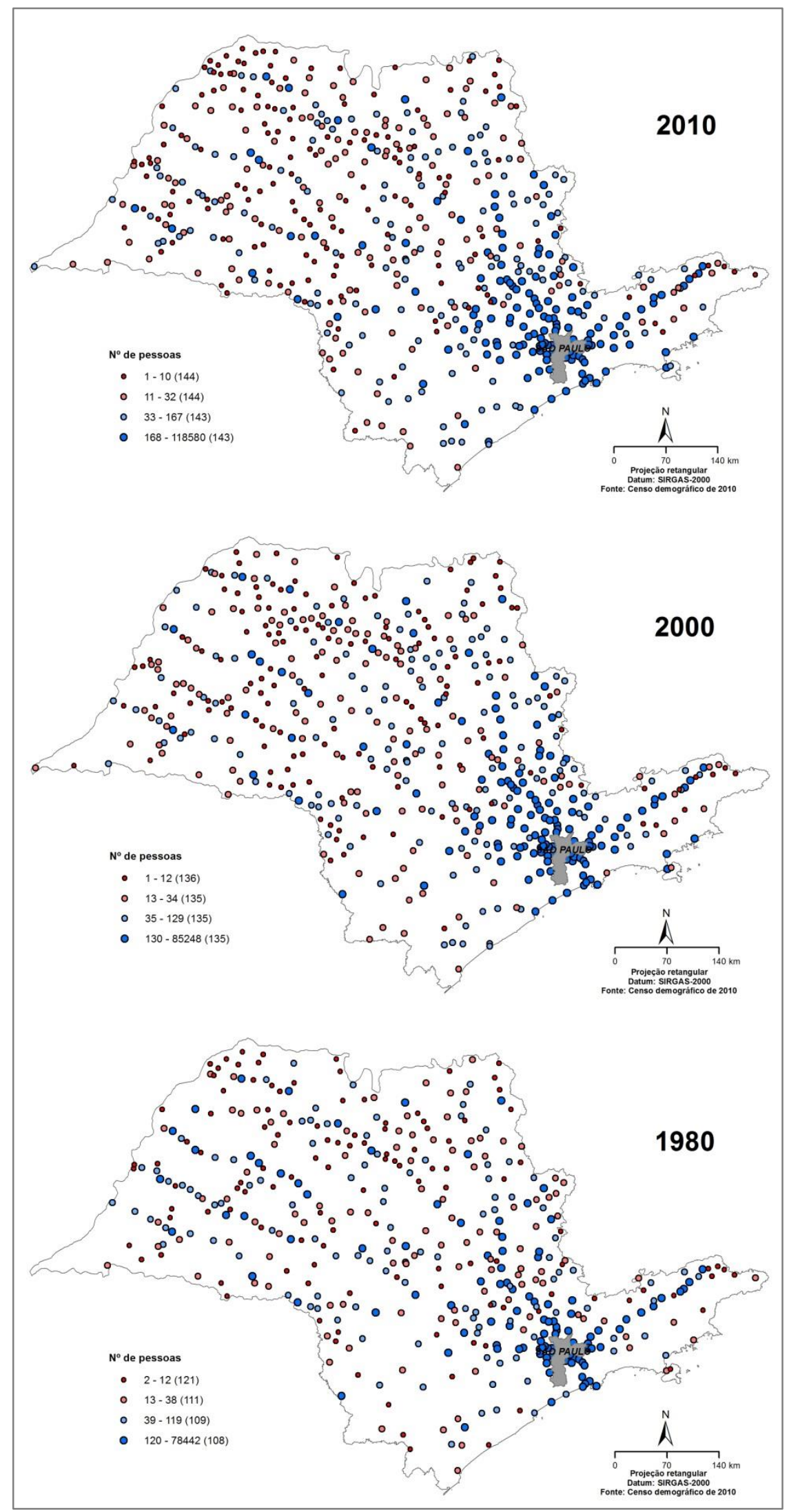

Figura 1: Razão de Pendularidade e Conectividade Pendular dos núcleos metropolitanos Brasileiros, 1980, 2000 e 2010 Fonte: IBGE, Censos Demográficos de 1980, 2000 e 2010 (dados da amostra) 


\section{CONSIDERAÇÕES FINAIS}

Desde a década de 1980, os possíveis efeitos do processo de desconcentração espacial e dispersão da população têm atraído atenção de vários pesquisadores brasileiros. Depois de décadas em que o país experimentou uma forte concentração da população e das atividades econômicas nas principais metrópoles do Sudeste, surgiram evidências de alteração do antigo padrão concentrador. A despeito de a realidade social e econômica brasileira ser distinta da dos países desenvolvidos, vários estudos buscaram avaliar a hipótese da "reversão da polarização" no Brasil. O debate ainda está vivo, embora sejam muitas as evidências a sugerir, se não uma desconcentração completa nos moldes clássicos dos países desenvolvidos, pelo menos um significativo aumento do grau de comutação nas principais metrópoles do país e incremento de muitas espacialidades externas ao núcleo das regiões metropolitanas.

De todo o modo, são ainda incipientes as pesquisas que esquadrinham a diversidade de movimentos espaciais da população no âmbito desse tipo de análise, seja tendo em conta a definição clássica de migração ou mesmo considerando a mobilidade pendular. Ainda que os resultados apresentados nesse paper sejam derivados de base de dados de apenas três décadas, o que requer cuidados em possíveis conclusões sobre tendências gerais, parece haver sinais de intensificação dos deslocamentos pendurares no espaço metropolitano do país, que tem atraído crescente e não desprezível número de trabalhadores e estudantes procedentes do interior de cada estado. Torna-se necessário, contudo, uma investigação mais aprofundada sobre a realidade de cada município, bem como a incorporação dos resultados obtidos pela análise dos próximos levantamentos censitários e da realidade das demais regiões metropolitanas do país, especialmente para os casos de São Paulo e Rio de Janeiro.

\section{REFERÊNCIAS BIBLIOGRÁFICAS}

Azzoni, C. (1986) Indústria e Reversão da Polarização no Brasil. Ensaios Econômicos - IPE/USP, São Paulo, n.58.

Brito, F.; Souza, J. (2005) Expansão Urbana nas grandes metrópoles: o significado das migrações intrametropolitanas e da mobilidade pendular na reprodução da pobreza. São Paulo em Perspectiva, v.19, n.4, p. 48-63,out/dez. 2005. Disponível em: 
$<$ http://www.scielo.br/scielo.php?

pid=S010288392005000400003\&

script $=$ sci_arttext> Acesso em 08 Jun. 2013

Cano, W. (1977) Raízes da Concentração Industrial em São Paulo, 2 ed. São Paulo: TA Queiroz.

Diniz, C.C. (1993) Desenvolvimento poligonal no Brasil; nem desconcentração, nem contínua polarização. Nova Economia - Revista de Ciências Econômicas da UFMG, Belo Horizonte, vol. 31, n. 11, pp. 35-64.

Greenwood, M. (1980) Migrações internas nos Estados Unidos; uma revisão da literatura. In: MOURA, A. M. (Coord). Migração interna; textos selecionados. Fortaleza: Banco do Nordeste do Brasil, 1980, p. 733-77. 1980.

Lobo, C. (2009) Dispersão espacial da população nas regiões de influência das principais metrópoles brasileira. Tese (doutorado) - Universidade Federal de Minas Gerais, Departamento de Geografia.

Lobo, C., Cardoso, L., Matos, R. (2009) Mobilidade pendular e centralidade espacial: considerações sobre o caso da Região Metropolitana de Belo Horizonte. In: XXIII ANPET - Congresso de Pesquisa e Ensino em Transportes. Vitória - ES.

Lobo, C., Matos, R. (2011) Migrações e a dispersão espacial da população nas regiões de Influência das principais metrópoles Brasileiras. Revista Brasileira de Estudos Populacionais, vol.28, no.1, p.81-101.

Martine, G. (1994) A redistribuição espacial da população brasileira durante a década de 80. Textos para Discussão 329, Brasília, IPEA, 43p.

Martine, G. (1987) Migração e metropolização. In: São Paulo em Perspectiva. São Paulo, Fundação SEADE 1(2)7.

Matos, R. (1995a) Dinâmica migratória e desconcentração da população na macrorregião de Belo Horizonte. Belo Horizonte. Tese (doutorado). Universidade Federal de Minas Gerais, CEDEPLAR.

Matos, R. (1995b) Questões teóricas acerca dos processos de concentração e desconcentração da população no espaço. In: Revista Brasileira de Estudos Populacionais, p.35-58.

Matos, R. e Ferreira, R. N. (2004). Inserção ocupacional de emigrantes das Áreas Metropolitanas de São Paulo e Rio de Janeiro. Revista Brasileira de Estudos da População, v. 21, n.1, p. 83-100. 
Matos, R. e Baeninger, R. (2004) Migração e urbanização no Brasil: processos de concentração e desconcentração espacial e o debate recente. Cadernos do Leste. IGC/UFGM, v.1, n.1, Belo Horizonte, 2004, p.7-44.

Negri, B. (1996) Concentração e desconcentração industrial em São Paulo (18801990). Campinas: Ed. UNICAMP.

OJIMA.R; Silva. B. R; Pereira. R. H. M. (2014) A Mobilidade Pendular na Definição das Cidades-Dormitório:caracterização sociodemográfica e novas territorialidades no contexto da urbanização brasileira. Disponível em : <www.abep.nepo.unicamp.br/docs/.../comunic_sec_1_mob_pen_def.pdf> Acesso em: 19. Fev. 2014

Patarra, N. (1984) Dinâmica populacional e urbanização no Brasil: período pós-30. In: Fausto, Boris, História geral da civilização brasileira: O Brasil republicano, São Paulo, Difel, t.3, v.4, 1984, p. 247-268.

Redwood III, J. (1984) Reversion de polarizacion, ciudades secundarias y eficiencia en el desarrollo nacional: una vison teorica aplicada al Brasil contemporaneo. Revista Latinoamericana de Estudios Urbanos Regionales, Santiago, vol 11, n.32, dez.

Richardson, H. (1980) "Polarization reversal in developing countries". The Regional Science Association Papers, Los Angeles, vol. 45, nov.

Rigotti, J. I. R. (1999) Técnicas de mensuração das migrações a partir de dados censitários: aplicação aos casos de Minas Gerais e São Paulo. Tese (doutorado em demografia). Belo Horizonte: UFMG/CEDEPLAR.

Rigotti, J. I. R. e Rodrigues, J. N. (1994) Distribuição espacial da população na região Metropolitana de Belo Horizonte. Anais do IX Encontro de Estudos Populacionais. Caxambú,1994, v.1, p.435-456

Taschner, S. P. e Bógus, L.M.M. (1986) Mobilidade Espacial da População Brasileira: Aspectos e Tendências. In: Revista Brasileira de Estudos de População, jul-dez.

Townroe, P. e Keen, D. M. (1984) Polarization reversal in the state of São Paulo, Brazil. Journal of the Regional Studies Association, Cambridge, vol. 18, n. 1, fev. 